\title{
PERSUASÃO: o componente pragmático da argumentação
}

\author{
Eduardo Chagas Oliveira*
}

\begin{abstract}
A publicação do Tratado da Argumentação: a nova retórica, em 1958, costuma suscitar, entre os adeptos dos estudos em argumentação, uma aproximação com a retórica de pensadores que vão de Corax e Tisias a Aristóteles e Quintiliano. Esse tipo de associação revela a temerária tendência para o entendimento de que a teoria erigida por Perelman constitui uma reconstrução da retórica aristotélica. Inicialmente, cumpre destacar que os campos de aplicação são efetivamente distintos. Ante ao estreito vínculo entre a retórica e a eloquência, que demarca os caracteres próprios da retórica na antiguidade, precisamos verificar que a nova retórica incorpora elementos da elaboração argumentativa - e, por conseguinte, do produto textual - que outrora não eram contemplados pelo campo retórico. Mesmo a Nova Retórica, jovem senhora sexagenária, não mais constitui um referencial para aquele que pretende irromper na árdua tarefa de analisar peças argumentativas. Tampouco a Novíssima Retórica, insculpida nas teorias sociojurídicas de Boaventura Sousa Santos, contempla os ambientes e modelos cognitivos próprios do atual contexto. As estratégias de persuasão, no mundo contemporâneo, ganharam contornos tão diferenciados, que pouco se parecem com aquelas indicadas em clássicos que se detiveram na tarefa de descrevê-las, como Aristóteles e Schopenhauer, por exemplo. Nossa abordagem, neste pequeno trabalho, restringe-se a contemplar o componente pragmático da argumentação - a persuasão-para configurar a existência de uma Nuper-retórica, capaz de contemplar o(s) ambiente(s) (preponderantemente) persuasivo(s) e a elaboração das peças argumentativas.

PALAVRAS-CHAVE: Retórica. Persuasão. Argumentação. Nuper-retórica.
\end{abstract}

A argumentação, per se, não traz consigo um componente pragmático. ${ }^{1}$ Seu vínculo com o real é secundário, uma vez que se trata de atividade, por natureza, indiferente a considerações de ordem prática, prescindindo desta para se constituir como tal. O amálgama entre a argumentação e sua aplicabilidade prática se manifesta pela capacidade de atração, notadamente ilustrada pela persuasão. Por esse motivo, nos limites da abordagem que será concedida no presente trabalho, designaremos como argumentação a ação sistemática de organizar fatos, ideias ou razões que, associados entre si, apresentam uma unidade capaz de conquistar a adesão de outros espíritos. Trata-se de um entendimento semelhante à proposta da pragma-dialética, que vê a argumentação como

\footnotetext{
* Doutor em filosofia. Professor da Universidade Estadual de Feira de Santana (UEFS).

Av. Transnordestina, s/n. Novo Horizonte. Cep: 44036900. Feira de Santana - Bahia - Brasil. echagas@uefs.br

${ }^{1} \mathrm{O}$ termo pragmático é utilizado, aqui, dentro dos ditames de uma interpretação relacionada ao campo da práxis. Em outras palavras, trata-se de uma acepção genérica, segundo a qual o verbete se mostra associado ao que contém vínculos com a esfera prática.
}

[...] uma atividade verbal, social e racional que visa convencer um crítico razoável da aceitabilidade de um ponto de vista, apresentando uma constelação de proposições que justificam ou refutam a proposição expressa pelo ponto de vista. ${ }^{2}$

Ora, qualquer ação ou atividade está associada a um fim. No caso da argumentação, esse fim se manifesta de dois modos: (I) pela persuasão, (II) pelo convencimento. ${ }^{3}$ Em outras palavras, quando uma argumentação não pretende persuadir, visa a convencer. Poder-se-ia abordar casos em que se pretende ir além do convencimento, sem descartálo. Esse terceiro entendimento, contudo, não será objeto de detalhamento, por considerarmos que, nessas situações, prevalece a motivação persuasiva (I), uma vez que o argumentante, insatisfeito Argumentation is a verbal, social, and rational activity
aimed at convincing a reasonable critic of the acceptability
of a standpoint by putting forward a constellation of
propositions justifying or refuting the proposition
expressed in the standpoint (Eemeren; Grootendorst,
2004, p.1).
${ }^{3}$ Já nos detivemos no tratamento dessa questão em ou-
tras oportunidades. Cf. Oliveira, Eduardo. Persuasão e
convencimento da teoria da argumentação de Perelman.
In: Chaïm Perelman: direito, retórica e teoria da
argumentação. Feira de Santana: NEF/UEFS, 2004. p.
67-80. 
com os efeitos produzidos pela argumentação que convence, procura - também - persuadir. Há, nesse caso, uma inversão de valores no tocante ao entendimento habitual, visto que a persuasão assume uma condição privilegiada ante o convencimento. No geral, costuma-se entender que a persuasão se encontra em uma condição inferior, por produzir crenças menos seguras e cativar por meios menos nobres, privilegiando as emoções e paixões, enquanto o convencimento conquista pela aproximação do caráter estritamente racional. Nossa acepção, contudo, pelo viés pragmático assumido, se vincula ao pressuposto segundo o qual,

[...] para quem se preocupa com o resultado, persuadir é mais do que convencer, pois a convicção não passa da primeira fase que leva à ação. Para Rousseau, [por exemplo] de nada adianta convencer uma criança 'se não se sabe persuadi-la' (Perelman, 1999, p. 30).

Uma argumentação pró-convencimento, terminologia mais adequada que argumentação convincente, ${ }^{4}$ busca desenvolver e consolidar um conjunto de crenças no indivíduo, conduzindo-o a aceitar justificativas que demonstram um caráter impessoal. Uma argumentação persuasiva, por sua vez, se caracteriza pelo fato de ser capaz de abrir flancos na resistência do interlocutor. Mostra-se, por conta disso, mais afeita à motivação de ações. Desencadeia um liame entre a vontade pessoal do indivíduo e as ideias que reiteram os seus interesses. Assim, munida de "forças atrativas", desenvolve uma propensão à ação. Essa é a razão pela qual estabelecemos a persuasão como componente pragmático da argumentação, responsável pela aproximação de interesses subjetivos (do argumentante e do seu interlocutor) e considerando-a capaz de figurar como força motriz para a realização de ações.

Consoante o entendimento que vê a argu-

${ }^{4}$ A utilização da terminologia convincente se mostra pouco ajustada ao propósito desta discussão, porque se associa ao aspecto de algo concludente, definitivo. Ao falarmos de uma argumentação pró-convencimento, estamos afastando a pretensão conclusiva, terminativa, porque a entendemos como um mecanismo que pretende, sem qualquer grau de certeza prévio, transmitir uma ideia de segurança, propensa a gerar, por assim dizer, um entendimento. mentação como um processo de adução de provas em torno de uma ideia que se pretende incutir no interlocutor, "Brandom entende a linguagem como uma forma de atuar: um jogo em que nós, seres humanos, fundamentalmente pedimos e damos razões” (Brandom apud Barrio, 2001, p. 26). Anuir ao proposto por Brandom equivale a compreender que a linguagem carrega consigo uma função argumentativa que lhe é endógena. Trata-se de uma sugestão perigosa, mas suficientemente instigante para nos provocar o desejo de tomá-la como premissa.

Resta saber, contudo, como se dá o movimento de demandar e ofertar razões. Três são as possibilidades. Na primeira delas, que designamos discursiva, o procedimento é alternado, os indivíduos possuem envergadura equivalente e se mostram igualmente aptos a conceder o que se lhes pede. Cada um deles cumpre uma função: (1) pedir razões, (2) dar razões. Na segunda, também alternada, o quadro se mostra análogo, mas ambos cumprem as duas funções (1 e 2). Designamos essa possibilidade como dialógica. Na terceira possibilidade, o procedimento é concomitante, há disputa, e os participantes constituem uma contenda diante da qual precisa haver um vencedor. As duas funções $(1,2)$ são cumpridas por ambos e ao mesmo tempo, exigindo rapidez nas decisões. Essa possibilidade é designada como contendedora. Não nos deteremos nas particularidades de cada uma dessas designações. Cumpre-nos, apenas, destacar que qualquer delas pode ser exercida por quem quer que seja. A argumentação discursiva, a dialógica e a contendedora são manifestações de linguagem que fruem do mesmo propósito - vindicar ou prover de razões - com resultados diversos: dispor (discursiva), compor (dialógica) ou impor (contendedora). Todas se movimentam no sentido da ação e são, por esse motivo, persuasivas. No entanto, ainda que quaisquer pessoas possam realizar o seu uso, não podemos ignorar que aceitamos o entendimento de que se trata de um jogo. Assim sendo, como em qualquer jogo, há os jogadores que: (a) dominam os fundamentos; (b) conhecem as técnicas; e aqueles que, para além de 
ambos (a, b), (c) sabem aplicar taticamente os conhecimentos que integram o conjunto de regras próprias do jogo. Esse savoir-faire corresponde à aliança entre teoria e prática; entre conhecimento e ação, nos domínios da argumentação persuasiva. Os jogadores que atingem esse nível de aplicação (c) procuram elaborar um levantamento prévio das peculiaridades do auditório e desenvolvem estratagemas que favoreçam o alcance das suas técnicas, para atingir a persuasão.

Ora, sendo a linguagem uma forma de atuar, um exercício, uma ação, sua aplicação requer estratégias. No limite, estratégias de ação. Estratégias do uso da linguagem que podem nos conduzir em uma discussão, no diálogo ou diante de uma contenda. O jogador deve dominar os fundamentos (a), conhecer as técnicas (b), mas não precisa ficar adstrito a elas. Pode, por exemplo, fazer uso de expedientes que não sejam previamente excluídos do processo; adotar técnicas oriundas de outros segmentos (jogos extralinguísticos) e aprimorar aquelas que pertencem à sua esfera (jogo), conseguindo tornar-se hábil e esmerado utilizador dos fundamentos e das técnicas. Esse aprimoramento, tal como a particular competência demonstrada por aqueles que são jogadores diferenciados e conseguem ir para além de ambos (a e b), justifica a genialidade de alguns em detrimento de outros que se mantêm no "lugar comum". Grandes oradores (Padre Antônio Vieira), exímios escritores (Machado de Assis) e programadores de excelência (Steven Jobs) estariam enquadrados nesse segmento, participando de cenários muito diferentes entre si, mas compondo peças argumentativas a serem expostas em ambientes persuasivos compatíveis com os meios e valores próprios dos seus respectivos contextos.

Vale ressaltar que, em qualquer dos cenários aludidos, há um jogo em que se movimentam perguntas e respostas, amparadas pelo condão da razão. Esta, por sua vez, oferece e avalia simultaneamente o rigor das justificativas que são apresentadas para sustentar a si mesma, em sua condição ontológica (de ser razão, no sentido de causa), e amparar argumentos ou ideias apresentadas como provas em torno de uma questão. Exemplo singular da razão que ampara o jogo de linguagem consiste no uso realizado pelo Padre Antônio Vieira em seus sermões. Conhecendo previamente o contexto e os valores admitidos pelo seu público, o seiscentista construía suas peças argumentativas para cativar os interlocutores diretos e inibir os contra-argumentos dos (potenciais) contendedores. O objetivo de Vieira, ao discursar, equivale ao que Perelman (1999, p. 17) designava como processo de formação de uma comunidade efetiva dos espíritos. Em suas palavras:

A formação de uma comunidade efetiva dos espíritos exige um conjunto de condições. O mínimo indispensável à argumentação parece ser a exigência de uma linguagem comum, de uma técnica que possibilite a comunicação.

Falar de uma linguagem comum equivale a reiterar o entendimento de que a linguagem é um instrumento de uso público. Sua apropriação privada não lhe retira a natureza pública que lhe é constituinte. Uma linguagem privada implica um contrassenso, uma vez que os usos da linguagem vindicam participantes que compartilham de signos e sentidos intercambiáveis. Wittgenstein, em Investigações Filosóficas, concede amplo tratamento acerca da(s) possibilidade(s) de alusão à linguagem privada, como se depreende daquilo que se costuma chamar de ALP (Argumento da Linguagem Privada), ${ }^{5}$ ao questionar os critérios para a existência de uma linguagem privada de natureza ostensiva.

Nossa abordagem não se atém a esse nível de tratamento. Nosso propósito é, antes, destacar o componente pragmático da argumentação. Assim, diante da possibilidade de concedermos atenção às preocupações atinentes às funções da linguagem, discutiremos e analisaremos como se processa a persuasão em um contexto em que se questiona a própria natureza da linguagem e suas variantes. Ou seja, nossa preocupação integra o rol

${ }^{5}$ Quando de fala de "argumento da linguagem privada", em Wittgenstein, quer se fazer alusão a um conjunto de argumentos dispostos no parágrafo 243 e seguintes (especificamente entre os $\S \S 243-315)$, das Investigações
Filosóficas. 
das jogadas possíveis dentro da partida, identificando as que são legais (obedecendo aos critérios previamente definidos), mesmo quando não persuasivas, e aquelas que se mostram ilegais (fora do escopo das normas), ainda que persuasivas.

A persuasão, para ser entendida como tal, precisa constituir ato voluntário do argumentante. Conforme enunciamos, a persuasão, que pode ser vista como um meio para a ação, é o fim que move o indivíduo a elaborar os seus argumentos. Desse modo, podemos dizer que, ao elencar os elementos que serão apresentados ao interlocutor, o argumentante procura compor uma peça argumentativa. Entendemos como peça argumentativa aquilo que poderíamos designar como discurso, por exemplo. Preferimos essa designação, no entanto, por entender que ela melhor se aproxima da esfera que nos serve de horizonte de investigação para as questões do ambiente persuasivo. Uma peça argumentativa, dentro das possibilidades acima descritas, pode ser constituída por estratagemas erísticos, palavras suasórias, disposições cromáticas, apelos emotivos, ideias convincentes, sutilezas sígnicas ou valores de reconhecida relevância no contexto. Esses ingredientes, associados entre si ou separadamente, permitem ao argumentante comunicar a sua ideia ou crença ou, mais comum, conquistar a aceitação do auditório à sua proposta. Encontra-se, nessa passagem, o detalhe acerca da diferença existente entre o argumento persuasivo e o fato persuasivo. Sobre o primeiro, já expressamos sua natureza, características e possibilidades. Cumpre-nos, agora, discorrer acerca do segundo e evidenciar sua distinção. Um fato persuasivo consiste na realização de um procedimento capaz de conduzir o indivíduo a uma "tomada de posição". Um olhar expressivo, amedrontador; a apresentação de um objeto perfurocortante, ou mesmo a exposição de uma arma de fogo; quiçá, um fenômeno da natureza. Argumentos persuasivos integram o rol dos fatos persuasivos, mas o inverso não se aplica de modo necessário; ou seja, nem todo fato persuasivo, conforme o breve elenco que enumeramos, corresponde a um argumento persuasivo.
Contrariamente ao caráter instrumental da hermenêutica, que procura aceder à interpretação das ideias presentes em uma plataforma textual, a retórica busca fomentar a capacidade de elaborar peças argumentativas eficazes. No limite da sua aplicação, a eficácia da argumentação persuasiva se constata mediante o numero e o grau de adesão que se conquista pela sua aplicação. Apresenta-se, nesse ponto, o deslocamento entre a concepção de retórica, nos moldes tradicionais, e a nova retórica edificada por Perelman (1993, p. 24-25), uma vez que essa última,

[...] em oposição à antiga, diz respeito aos discursos dirigidos a todas as espécies de auditórios, [...] a teoria da argumentação concebida como uma nova retórica (ou uma nova dialética) cobre todo o campo do discurso que visa convencer ou persuadir, seja qual for o auditório a que se dirige e a matéria a que se refere. Poder-se-á completar, se parecer útil, o estudo geral da argumentação com metodologias especializadas segundo o tipo de auditório e o gênero da disciplina. Poder-seia, assim, elaborar uma lógica jurídica ou uma lógica filosófica, que mais não seriam do que aplicações particulares da nova retórica ao direito e à filosofia.

Como uma metodologia, a nova retórica se mostra um método lógico, confiável e racional, mas de uma racionalidade que não se funda no critério de evidência; pelo contrário, recusa-o. Trata-se de uma racionalidade que se aproxima do razoável, do verossímil, do provável, do qual fala Aristóteles ao descrever o método e as provas dialéticas. A linguagem ou argumentação utilizada pela nova retórica é de natureza lógico-dialética. Lógica, porque estuda os meios de prova; e dialética, porque não se funda em provas formais, rigorosas e coercivas, mas busca algo próximo dessa solidez através das opiniões originárias do (e embasadas pelo) senso comum e endossadas pelo crivo da razão compartilhada (Perelman, 1999, p. 575). A nova retórica, portanto, se propõe a ser uma modalidade de lógica em sentido alargado, capaz de contemplar aspectos próprios da retórica, da lógica e da hermenêutica, motivo pelo qual o próprio Perelman (1999, p. 5) declara que mais adequado seria designá-la como uma nova dialética, tendo 
evitado essa nomenclatura em virtude da aproximação entre o termo e a tradição pós-hegeliana. Há razões que o fizeram preferir uma aproximação com a retórica.

A primeira delas é o risco de confusão que [a] volta a Aristóteles poderia trazer. Pois se a palavra dialética serviu, durante séculos, para designar a própria lógica, desde Hegel e por influência de doutrinas nele inspiradas ela adquiriu um sentido muito distante de seu sentido primitivo, geralmente aceito na terminologia filosófica contemporânea.

A novíssima retórica, remanescente da Crítica da razão indolente de Boaventura de Sousa Santos (2002), poderia ser suscitada como uma resposta adequada para o problema da articulação entre conhecimento e ação, uma vez que Santos se debruça sobre os modelos de pensamento da sociedade ocidental contemporânea, estabelecendo uma concepção pragmática do conhecimento e, por conseguinte, da ideia de verdade. O problema é que a novíssima retórica possui um caráter demasiadamente sociológico, desprezando a questão argumentativa e centrando sua abordagem no campo dos auditórios, contemplando elementos argumentativos e não argumentativos, por entender que, "sem ter em conta a dialética entre momentos argumentativos e não argumentativos, é impossível entender a construção e a destruição sociais de auditórios e comunidades." (Santos, 2002, p. 106). A limitação da proposta de Santos reside no fato de ser a novíssima retórica uma teoria sociológica da retórica, em vez de se constituir como uma teoria da argumentação. Por esse motivo, cumpre-nos resgatar as críticas de Santos à nova retórica de Perelman, para pensar o escopo de uma nuper-retórica. Alves e Ferres (2003, p. 35) sintetizam as críticas de Santos, destacando que

Os pontos falhos da nova retórica de Perelman estariam em ser ela: (a) técnica, pois não consegue adjudicar entre a persuasão e o convencimento; (b) manipuladora, uma vez que os oradores apenas influenciam e não se consideram influenciados pelo auditório, o que ressalta o protagonismo do orador; (c) estática, pois prevê uma estabilidade e duração das premissas, ou seja, uma permanência dos pontos de partida das discussões; e (d) imutável, uma vez que apresenta um auditório dado, fixo, uma comunidade que não reflete os processos sociais de inclusão e exclusão.

Ora, a nova retórica não tem a pretensão de adjudicar persuasão e convencimento, porque são atividades distintas que podem (ou não) articularse. Conforme enunciamos, a persuasão traz consigo o caráter pragmático do qual a argumentação próconvencimento estaria desprovida. No que se refere ao caráter manipulador, não acreditamos na passividade dos auditórios, conforme parece sugerir Santos; outrossim, o foco da nova retórica, contrariamente às retóricas da antiguidade, não está centrado na figura do orador, mas dos argumentos. Quanto à condição estática e imutável, poderíamos condensá-la na designação de utopia axiológica, uma vez que há pretensão de sugerir a existência de valores imutáveis e pontos de partida de caráter universal. Essas fragilidades da nova retórica, não superadas pela novíssima retórica de Santos, dão azo à possibilidade de uma nuper-retórica.

A concepção de uma nuper-retórica incorpora elementos próprios da estruturação perelmaniana, mas sugere uma inversão de algo proposto pela teoria hermenêutica de Schleiermacher, numa perspectiva que antepõe a hermenêutica à retórica, embora amparando esta naquela. Schleiermacher sugere que

[...] para a compreensão do outro [é preciso que] a gente se transforme nele o mais perfeitamente possível e se equipare a ele, apropriando-se da situação histórica, das circunstâncias concretas da vida e intenções, das formas de pensamento, dos modos de representação e expressão, a fim de entendê-los pela reprodução deles (Schleiermacher apud Coreth, 1973, p. 114).

Esse entendimento indica, como ação eminentemente hermenêutica, a capacidade de o intérprete penetrar no espírito da obra e ter em conta a personalidade do seu autor, criando com ele uma empatia. Em sentido contrário, mas amparando-se em construção análoga, acompanhamos o pensamento de Perelman (1999, p. 4), que compreende ser possível construir uma competência do orador (argumentante) em aceder ao espírito do auditório 
(interlocutor), ter em conta os valores que por ele são admitidos, criando, com ele, uma (suposta) identidade, para conseguir convertê-lo ao assentimento, pois “toda argumentação visa à adesão dos espíritos e, por isso mesmo, pressupõe a existência de um contato intelectual.” (Perelman, 1999, p. 16). De modo complementar, propõe:

Nos campos jurídico, político [e] filosófico os valores intervêm como base de argumentação ao longo de todo o desenvolvimento. Recorre-se a eles para motivar o ouvinte a fazer certas escolhas em vez de outras e, sobretudo, para justificar estas, de modo que se tornem aceitáveis e aprovadas por outrem (1999, p. 84-85).

Trata-se da forja como estratégia de estruturação de argumentos. Uma argumentação eficaz é construída como uma peça em bronze que se elabora pela disposição do metal em consonância com a habilidade do ferreiro, donde se entende a condição da "peça argumentativa”. Um exemplo de como se forja uma peça dessa natureza, para a conversão de incautos interlocutores ao assentimento das suas ideias, está previsto, de modo exemplar, no entendimento que Bourdieu nos oferece acerca dos "usos do povo", ao ressaltar, em especial, aquilo que ocorre "no campo político, onde se pode jogar com todas as ambiguidades da palavra "povo" (classes populares, proletariado ou nação, volk.)” (Bourdieu, 2004, p. 181). Há de se ressaltar, cautelarmente, que o uso apropriado da palavra - inserida em um contexto - para a composição de uma peça argumentativa, não pode ser confundido com discrepâncias decorrentes do uso sorrateiro das ambiguidades associadas ao conceito. Nesse outro caso, estaríamos a tratar de falácias não formais de ambiguidade, que, no limite, consistem em pseudo-argumentos. Não é o caso!

$$
* * *
$$

O presente texto, pelo seu próprio caráter preambular, resgata os elementos que servem para consubstanciar uma nuper-retórica, calcada nos pressupostos da ação voluntária, no interesse da persuasão e ajustada a um modelo de comportamento ou pensamento que se pauta na ideia de
Fast Thinking (Bourdieu, 1997, p. 38-42). Bourdieu, ao tratar da formatação da sociedade dos mass media, concedeu rigoroso tratamento à questão da presença da televisão na construção de identidade da sociedade contemporânea. Embora seja uma abordagem relativamente recente, uma vez que Bourdieu faleceu em 2002, o seu tratamento não pôde contemplar a sociedade digital, os processos de inclusão ou exclusão digital e os caracteres associados a esse novo modelo. Convivemos com uma realidade em que a linguagem está diretamente associada à imagem. Não se trata, contudo, de coisas intercambiáveis, mas complementares. Há uma imagem que diz, comunica, expressa, transmite por sinais, cativa e converte. Essa linguagem transcende o campo do verbal indicado por Eemerrn e Grottendorst (2004) em sua pragmadialética, mas permanece ligada ao ambiente persuasivo das peças argumentativas, implicando uma forma de argumentação não verbal, cujos modelos de retórica - da antiguidade às pretensões da novíssima retórica - não contemplaram. Aquilo que designamos como argumentação não verbal, corresponde à colaboração argumentativa de elementos e componentes não verbais, de grande valor persuasivo. Trata-se de uma argumentação, porque não deixa de ser uma forma de apresentar justificativas para uma ideia que se pretende incutir em outrem, mas foge do escopo verbal, porque não comporta a oralidade, sem, contudo, desprezá-la.

Dentro do contexto argumentativo que nos serve de referência, a linguagem é tratada como um dispositivo que conecta o horizonte do mundo (interlocutores) ao horizonte do ser (argumentante). Decorre dessa conexão a proximidade com a hermenêutica. O deslocamento, no entanto, se processa pela finalidade, uma vez que o nosso propósito é evidenciar o componente pragmático desse processo de conexão: a persuasão. Por esse motivo, não se trata de uma abordagem hermenêutica, tampouco ontológica, mas de matiz nuper-retórica.

Recebido para publicação em 10 de outubro de 2012 Aceito em 04 de novembro de 2012 


\section{REFERÊNCIAS}

ALVES, Marco Antônio Sousa; FERES, Marcos Vinício Chein. Para uma ciência e um direito pós-modernos. Revista da Faculdade de Direito Milton Campos, [S.l.], v.10, p. 17-55, 2003. Disponível em: http://migre.me/aP4sl. Acesso em: 22 set. 2012

BARRIO, Eduardo Alexandre. Hacer explícitos los limites del mundo. In: SMITH, Plínio Junqueira; RUFFINO, Marco; PINHEIRO, Ulysses (Org.). Ontologia, conhecimento e linguagem. Um encontro de filósofos latino-americanos. Rio de Janeiro: Paperj/MAUAD, 2001. p.25-32.

BOURDIEU, Pierre. Coisas ditas. Trad. Cássia R. da Silveira e Denise Moreno Pegorim. São Paulo: Brasiliense, 2004. $\overline{1997 .}$

Sobre a televisão. Rio de Janeiro : Jorge Zahar,
BRANDOM, R. Articulating reasons. Cambridge: Harvard U.P., 2000.

CORETH, Emerich. Questões fundamentais de hermenêutica. Trad. Carlos Lopes de Matos. São Paulo: EPU, 1973.

EEMEREN, Frans van; GROOTENDORST, Rob. Systematic theory of argumentation. Cambridge: Cambridge University Press, 2004.

OLBRECHTS-TYTECA, Lucie. Tratado da argumentação: a nova retórica. São Paulo: Martins Fontes, 1999.

PERELMAN, Chaïm. O império retórico. Porto: ASA, 1993.

SANTOS, Boaventura de Sousa. Crítica da razão indolente: contra o desperdício da experiência. São Paulo: Cortez, 2002.

WITTGENSTEIN. Ludwig. Investigações filosóficas. São Paulo: Abril, 1979. (Coleção os pensadores). 


\section{PERSUASION: the pragmatic component of argumentation}

\section{Eduardo Chagas Oliveira}

The New Rhetoric: ATreatise on Argumentation, published in 1958, is usually associated by argumentation scholars with the rhetoric of thinkers ranging from Corax and Thysias to Aristotle and Quintilian. This type of association reveals the doubtful tendency to take Perelmann's theory as a reconstruction of Aristotelian rhetoric. It is worth noticing that these have actually distinct fields of application. In face of the narrow bound between rhetoric an eloquence, which draws the characteristic features of ancient rhetoric, one must reckon that the new rhetoric incorporates elements of argumentative elaboration - and thus of the textual product - which were not then contemplated in the rhetorical field. Even the New Rhetoric no longer stands as reference to those wishing to be initiated in the hard task of analyzing argumentative pieces. Also the New Rhetoric, engraved in socio-juridical theories of Boaventura Sousa Santos, does not contemplate the present time cognitive environment and models. Today, persuasion strategies have assumed features which are so differentiated that they hardly resemble those pointed out in classics dedicated to describe them, such as Aristotle and Schopenhauer. Our approach consists in contemplating the pragmatic component of argumentation - persuasion - so as to configure the existence of a Nuper-rhetoric capable of contemplating the (mainly) persuasive environment(s) and the elaboration of argumentative pieces. Jurídica.

\section{PERSUASION: La composante pragmatique de l'argumentation}

\section{Eduardo Chagas Oliveira}

La publication, en 1958, du Traité de l'Argumentation: une nouvelle rhétorique, suscite en général parmi les adeptes de l'étude de l'argumentation un rapprochement avec la rhétorique de penseurs allant de Corax et Tisias à Aristote et Quintilien. Ce type d'association révèle une tendance téméraire de considérer la théorie érigée par Perelman comme une reconstruction de la théorie aristotélicienne. Au départ, il convient de noter que les champs d'application sont effectivement distincts. Face au lien étroit qui existe entre la rhétorique et l'éloquence qui démarque les caractères propres de la rhétorique dans l'antiquité, il faut vérifier si la nouvelle rhétorique intègre les éléments de l'élaboration argumentative - et par conséquent du produit textuel - qui autrefois ne faisaient pas partie du champ rhétorique. Même la Nouvelle Rhétorique, jeune dame de soixante ans, n'est plus une référence pour celui qui veut se lancer dans la dure tâche d'analyse des pièces d'argumentation. Ni même la Très Nouvelle Rhétorique, contenue dans les théories socio-juridiques de Boaventura Sousa Santos, prend en considération les milieux et les modèles cognitifs du contexte actuel. Les stratégies de persuasion du monde contemporain ont acquis des formes tellement différenciées qu'elles ressemblent peu à celles citées dans les classiques qui se sont contentés de les décrire, comme Aristote et Schopenhauer par exemple. Notre approche, dans cette étude, se limite à prendre en considération la composante pragmatique de l'argumentation - la persuasion - pour définir l'existence d'une Nuperrhétorique capable de contempler le(s) milieu(x) (surtout) persuasif(s) et l'élaboration de pièces argumentatives.

KEY-wORDS: Rhetoric. Persuasion. Argumentation. Mots-CLÉs: Rhétorique. Persuasion. Argumentation. Nuper-rhétorique.

Eduardo Chagas Oliveira - Doutor em Filosofia. Professor da Universidade Estadual de Feira de Santana. Coordenador do Núcleo Interdisciplinar de Estudos e Pesquisas em Filosofia e Editor Responsável pela Revista Ideação (UEFS). Consultor de Projetos Educacionais da Secretaria de Educação do Estado da Bahia. Possui experiência na Formação de Professores, especialmente nas Licenciaturas do Programa Nacional de Formação de Professores (PROFORMA), da Plataforma Freire. No campo das investigações acadêmicas, concede maior ênfase aos conteúdos associados à Ética, Teoria da Argumentação, Hermenêutica e Epistemologia 